\title{
Crisis management and the industrial psychologist: Why do we shy away?
}

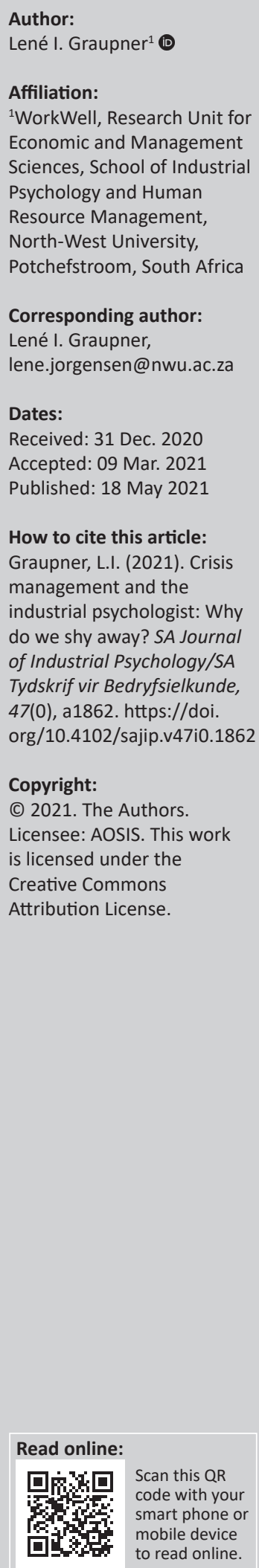

\section{Introduction}

None of us were prepared for the way we found ourselves in this new age of work. Coronavirus disease-2019 (Covid-19) brought many changes and adjustments to life in general, as well as in the workplace. The pandemic's onset led to most employees living and working in a high-stress environment worldwide for months. Apart from the physical threat to humanity that Covid-19 caused, the size and scope of the economic crisis it caused are the largest we have ever seen in our lifetime (Krugell, 2020). Suddenly, certain jobs became redundant or businesses closed that could not cope with switching to a virtual world. Initially, lighthearted reports were posted on social media by employees working from home in pyjamas. However, soon these reports had a theme of fear and loss as the infection rate increased, incomes and job securities decreased and family members were traumatised as some passed away in isolation because of Covid-19 (Neal, 2020).

The call for articles for this special edition states 'it is our hope as industrial and organisational psychologists, to contribute, respond, facilitate, and also influence in meaning and sense-making of the impact of the Covid-19 pandemic...' (AOSIS, 2020). In order to answer this call we as industrial and organisational psychologists (IOPs) need to fully understand our responsibility during crisis management. It is my opinion that we as IOPs are poorly prepared and equipped for such a task. Even more so, it looks like IOPs shy away from abnormal behaviour in the workplace because it seems to fall in a clinical scope (Neal, 2020). Therefore, in this article, I will focus on industrial psychologists being the practitioners in the workplace who are supposed to support and facilitate meaning to employees during Covid-19, employing a crisis management role.

Industrial psychologists often are the first line of contact for distressed employees in organisations (Neal, 2020). Consequently, as psychologists, we should be able to identify distressed employees and implement interventions, such as crisis counselling and workplace counselling, to support these individuals (HPCSA, 2019b). The importance of this role was reiterated in a webinar presented by the Society for Industrial and Organisational Psychology in South Africa (SIOPSA), where Neal (2020) stated that not many employees have access to healthcare in the work environment and that IOPs could be the only practitioners who can assist and refer on the frontline.

Apart from industrial psychologists being able to observe and diagnose human behaviour, the practitioner should also design and implement interventions that are applied the individual, group and organisational levels (HPCSA, 2019b). From an occupational health psychology perspective, counselling-related interventions are relevant for each of these levels. For example, having a wellness policy on organisational (primary) level, psychological-educational workshops on group (secondary) level and providing a reactive and recuperative counselling service on an individual (tertiary) level (Giga, Cooper, \& Faragher, 2003). Form 218 (HPCSA, $2019 \mathrm{~b}$ ) indicates it is expected of industrial psychologists to be able to provide systemic and individual interventions to attend to work-related dysfunctions, stress, anxiety and issues relating to performance. From a career psychology approach, employees should be supported to manage insecurity and instability in the workplace, which could cause feelings of anxiety (Savickas, 2012). Industrial psychologists can play a major role in addressing anxiety experienced by individuals relating to career-related issues such as retrenchment, redundant positions, technological advances and the changing work environment (Mayer \& Oosthuizen, 2021). Protecting employees from burnout requires interventions aimed at emotional regulation in the form of adaptive coping strategies (Bimrose \& Hearne, 2012). Implementing such interventions falls within the scope of the industrial psychology field.

However, it is the opinion of many IOPs that counselling falls out of their scope of practice. During the recent SIOPSA 2020 annual conference, a feedback session on the general problems 
found during the Health Professions Council of South Africa's (HPCSA) board examination indicated that most IOP interns did not view themselves as psychologists or behavioural scientists (Van Vuuren, 2020). Furthermore, most candidates could not diagnose workplace psychopathology. A major area of concern was that the candidates believed that they would rather refer employees for counselling than provide counselling or crisis counselling themselves. Some candidates indicated that they should not become involved in counselling and were advised to refer employees in need of counselling (Van Vuuren, 2020). These candidates were recently under training and are supposed to know the official HPCSA documents stating that it is our responsibility to provide psychological support and counselling. In fact, no fewer than four HPCSA documents declare this responsibility (Department of Health, 2008, 2010; HPCSA, 2019a, 2019b). For this article, I am arguing that we are both psychologists and behavioural scientists although we are bound to our scope of practice, we primarily function in a scope of a profession with fellow psychologists, with the same responsibility to serve humankind.

\section{The scope of profession}

Even though the scope of profession (Department of Health, 2008 , p. 3) describes the acts, especially pertaining to psychology, I get the sense that we somehow have the perception that as IOPs we are excluded from the scope of profession. I sense that we are so afraid of being out of our scope of practice that we are actually not functioning entirely in our scope. We are therefore not effectively helping those who need assistance as set out in our own training guidelines. It is my opinion that we fail to assist distressed employees because of being overly cautious. The profession's scope clearly states that we should be able to rectify and relieve adjustment problems or mental deficiencies of individuals or groups of people (Department of Health, 2008). In addition to the scope of the profession as prescribed in the regulations by the HPCSA, the scope of practice of IOPs guides our role in more detail.

\section{The scope of practice}

The scope of practice for IOPs states clearly how the role of industrial psychologists in the workplace should be implemented. We should be able to (Department of Health, 2010, p. 9):

- Apply psychology principles in the workplace

- Develop interventions to ameliorate poor performance

- Implementindustrial psychology intervention programmes.

These two scopes, referred to here, imply that we are trained behavioural scientists who are supposed to be able to identify and diagnose human behaviour to enhance poor performance and address adjustment problems. We should remedy behaviour, rectify and relieve emotional, behavioural or adjustment problems by utilising psychological counselling to prevent mental illnesses of employees (Department of Health (South Africa), 2008). Somehow, we exclude our role of crisis counsellor or workplace counsellor from our skill set when indeed we should be training our students for so much more, as stated in the minimum standards of training (standards generating body [SGB]) document (HPCSA, 2019a).

\section{Minimum standards of training}

According to the guidelines in the SGB document, the rationale and purpose of obtaining a master's degree in industrial psychology are to produce 'competent, ethical and professional industrial psychologists who can meet the psychological needs of the people living in South Africa' (HPCSA, 2019a). One of the minimum exit-level outcomes an IOP student should show is (HPCSA, 2019a, para. b, p. 4):

- Knowledge of the theory and practice of more than three evidence-based models of psychological therapy.

Furthermore, the student should be able to (HPCSA, 2019a, para. c, p. 4):

- Assess workplace-related psychopathology such as 'trauma, stress and burnout, competence, motivation and performance'.

What is especially interesting and relevant for Covid-19 is that the document explicitly states that the student should be trained to:

- Provide short-term counselling as part of individual and systemic interventions such as post-trauma counselling, crisis counselling, and job stress-related counselling (HPCSA, 2019a, para. d, p. 5).

Moreover, master's students should be trained in the principles of psychology to:

- Identify, understand and manage physical and psychological health challenges that influence employees' functioning (HPCSA, 2019a, para. 1, p. 6).

It is reasonably clear that the responsibility to support employees with health challenges in the current times we are facing with Covid-19 is squarely in the domain of industrial psychology. Apart from training our students in these principles, the HPCSA (2019b) thoroughly documented how we should guide their internships in form 218 , which is even more applicable to the role of counsellor.

\section{Requirements in respect of internship programmes in industrial psychology}

The internship content guidelines for career psychology and employee wellness and well-being show that the following activities need to be included in this domain (HPCSA, 2019b, para. 3.1.3, p. 7):

- The diagnosis of workplace-related psychopathology and general psychopathology

- A sufficient component of basic counselling skills including: crisis counselling, trauma debriefing and performance counselling 
- Appropriate referral procedures for further diagnosis and treatment of workplace-related and general psychopathology.

Although an important note (HPCSA, 2019b, p. 7) is made that industrial psychologists do not provide psychotherapy, the guidelines state that our role is limited to:

- Diagnosis of workplace-related psychopathology and the recognition of the need for further treatment and psychological intervention

- Interns should demonstrate their involvement in interventions to attend to work-related dysfunctions (HPCSA, 2019b, p. 7).

Relating to managing Covid-19 in the workplace, form 218 provides a fundamental guideline, namely that it is the responsibility of IOPs to address the physical and psychological health issues of employees (HPCSA, 2019b, p. 8). Furthermore, form 218 states that the impact of negative economic circumstances on the psychological well-being of employees should be addressed by IOPs (HPCSA, 2019b, p. 8). This sounds very familiar within the current scenario of Covid-19 and is viewed as the very limit of the services we should be able to provide.

Therefore, we have a clear boundary as to where we fit in regarding psychological support in the workplace; yet, why do we shy away? Why do we so often say, this is not in our scope? In my opinion, several reasons can be listed, such as:

- Not having a suitable counselling skill-set to apply

- Fear and lack of confidence to address trauma-related symptoms

- A lack of being able to identify signs and symptoms of workplace-related psychopathology and thereby avoiding it altogether

- Not fully understanding the identity and value of the IOP.

In the last section of this article, I provide recommendations on how to apply our role as counsellors in the workplace.

\section{Recommendations for practice and policy Standardised training curriculum}

It is essential for lectures at tertiary institutions to offer a combined effort towards a curriculum in training students in crisis and counselling intervention approaches. Although I have made an effort to develop such a counselling framework in recent years (Jorgensen, 2016; Jorgensen-Graupner, 2019; Jorgensen-Graupner et al., 2019), much work is still needed to refine such an approach for IOPs. Therefore, a standardised counselling approach for IOPs to accurately identify (diagnose) and address the whole spectrum of problems employees face, should be developed, including generating short learning programmes as part of the continuous professional development (CPD) programme for practitioners to update their professional knowledge and skills (HPCSA, 2017). Furthermore, students should be trained on primary, secondary and tertiary interventions, specifically relating to the field of occupational health psychology. This implies how counselling should be incorporated into each level in order to efficiently support the organisation, team and individual.

In order not to shy away from our role as workplace counsellors, as stated in the title of this article, we should first exhaust the full spectrum of our skill-set. Consequently, if it is not possible to intervene suitably, we should know how to refer appropriately (HPCSA, 2019b, para. 3.1.3, p. 7). Referral is a very specialised skill, and we will only be able to effectively manage a referral if we know what to refer. For that reason, the importance of training students in psychology principles, psychopathologies and abnormal behaviour cannot be overemphasised (Neal, 2020). In addition, we should be skilled in the principles of psychology by knowing the classification of mental disorders as published in the Diagnostic and Statistical Manual of Mental Disorders, 5th Edition (DSM-5) (APA, 2013) to refer accurately.

\section{Healthcare network}

In addition, we also need to understand our fellowpsychologists' scopes to suitably refer. We should see ourselves as part of a healthcare network and know the networks available to us in our immediate area by keeping a register of details for easy access for referrals. For example, such a register should include contact details of social workers, psychologists (in all categories), psychiatrists, psychiatric facilities, SA depression and anxiety group (SADAQ), alcoholics anonymous (AA), rape support centres and the Family and Marriage Society of South Africa (FAMSA) (to name a few).

\section{Value proposition}

Apart from IOPs understanding their role as counsellors during crisis management in the organisation, equally important is our value proposition to the employees in the workplace. Such a value proposition should clearly show how IOPs can address the employees' counselling demands, amongst other needs. It should communicate to employees the details of the advantages and reasons for utilising IOPs as counsellors in the workplace. However, this is a prospect to be explored in further research.

\section{Conclusion}

As we face a worldwide pandemic, now is the time to step up and upskill to our full potential as IOPs. If we do not step up, someone could suffer, and we ironically run the risk of doing more harm by denying a distressed employee immediate assistance or referring too hastily. To make a difference during the period of Covid-19, or any other crisis, we should use the full spectrum of our behavioural science with confidence, ceaselessly serving humankind. 


\section{Acknowledgements Competing interests}

The author declares that she have no financial or personal relationships that may have inappropriately influenced her in writing this article.

\section{Author's contributions}

L.I.G. is the sole author of this opinion article.

\section{Ethical considerations}

Ethical clearance (reference number NWU-00955-20-A4) was granted by the Economic and Management Sciences Research Ethics Committee (EMS-REC) at the North-West University, Potchefstroom.

\section{Funding information}

This research received no specific grant from any funding agency in the public, commercial or not-for-profit sectors.

\section{Data availability}

Data sharing is not applicable to this article as no new data were created or analysed in this study.

\section{Disclaimer}

The views and opinions expressed in this article are those of the author and do not necessarily reflect the official policy or position of any affiliated agency of the author.

\section{References}

American Psychiatric Association (APA). (2013). Diagnostic and statistical manual of mental disorders (5th edn.). Arlington, VA: American Psychiatric Association.

AOSIS. (2020). Call for papers: South African Journal of Industrial Psychology (SAJIP) Special COVID-19 issue. Retrieved from https://aosis.co.za/call-for-papers-southafrican-journal-of-industrial-psychology-sajip-special-covid19-issue/?mc cid=b7f0ec9c2e\&mc_eid $=837$ c460757
Bimrose, J., \& Hearne, L. (2012). Resilience and career adaptability: Qualitative studies of adult career counseling. Journal of Vocational Behavior, 81(3), 338-344. https://doi.org/10.1016/j.jvb.2012.08.002

Department of Health (South Africa). (2008). Health Profession Act, 1974 (Act no. 56 of 1974): Regulations defining the scope of the profession of psychology (notice 993). Government Gazette, 31433, pp. 3-6. Pretoria: Government Printer.

Department of Health (South Africa). (2010). Health Profession Act, 1974 (Act no. 56 of 1974): Regulations defining the scope of practice of practitioners of the profession of psychology (notice 263). Government Gazette, 33080, pp. 3-11. Profession of psychology (notic

Giga, S.I., Cooper, C.L., \& Faragher, B. (2003). The development of a framework for a comprehensive approach to stress management interventions at work. International Journal of Stress Management, 10(4), 280-296. https://doi. org/10.1037/1072-5245.10.4.280

Health Professions Council of South Africa (HPCSA). (2017). Continuing professional development guidelines for the health practitioners. Retrieved from https://www. hpcsa.co.za/Uploads/Professional_Practice/CPD/CPD\%20Guidelines\%20 Sept $\% 202017$.pdf

Health Professions Council of South Africa (HPCSA). (2019a). The board of psychology. Minimum standards for the training of industrial psychologists. Retrieved from https://www.hpcsa.co.za/Uploads/PSB_2019/Policy\%20and\%20Guidelines/ SGB $\% 2$ INDS $\% 20-\% 20$ Revised $\% 200$ ctober\%202019.pdf

Health Professions Council of South Africa (HPCSA). (2019b). The board of psychology Guidelines for universities, internship training institutions and intern industrial psychologists. Form 218. Retrieved from https://www.hpcsa.co.za/Uploads/ PSB_2019/Form\%20218\%20INDS\%20-\%20Requirements\%20in\%20 Respect $\% 20$ of $\% 20$ Internship $\% 20$ Programmes $\% 20$ in $\% 20$ Industrial $\% 20$ Psychology $\% 20 \% 20 . p d f$

Jorgensen, L.I. (2016). Encounter group counsellor training with pre-service industria psychologists: A pilot study. Journal of Psychology in Africa, 26(3), 300-303. https://doi.org/10.1080/14330237.2016.1185920

Jorgensen-Graupner, L.I. (2019). A counselling framework for industrial psychology practitioners. 19th congress of the European association of work and organisational psychology (EAWOP), Turin, Italy, 28 May-2 June 2019.

Jorgensen-Graupner L.I., \& Van Zyl, L.E. (2019). Inspiring growth: A counselling framework for industrial psychology practitioners. In S. Rothmann \& L. Van Zy (Eds.), Positive psychological interventions: Theories, methodologies and applications within multi-cultural contexts. Cham, Switzerland: Springer.

Krugell, W. (2020). Farmers, markets and consumers. Guest Speaker at NWU \& AMT Agri live outlook conference, 22 April 2020. Retrieved from https://www.youtube. $\mathrm{com} /$ watch?v=3V04PBMlfis

Mayer, C.H., \& Oosthuizen, R.M. (2021). Anxiety and excitement in the fourth industrial revolution: A systems-psychodynamic perspective. SA Journal of Industrial Psychology, 47(2), 13. https://doi.org/10.4102/sajip.v47i0.1813

Neal, A. (2020). Managing abnormal behavior in the workplace from a crisis management perspective. Guest speaker at Keep Calm and Carry on webina series organised by the Society for Industrial and Organisational Psychology South Africa, South Africa, 21 April 2020

Savickas, M.L. (2012). Life design: A paradigm for career intervention in the 21st century. Journal of Counseling \& Development, 90(1), 13-19. https://doi. org/10.1111/j.1556-6676.2012.00002.x

Van Vuuren, L. (2020). IOP Board exam feedback and guidelines. Presentation at the virtual annual conference of the society for Industrial and Organisational Psychology South Africa (SIOPSA), 1-3 December 2020, Pretoria, South Africa. Retrieved from: https://www.siopsa.org.za/2020-conference/ 